\title{
Conservative management of leakage after laparoscopic sleeve gastrectomy
}

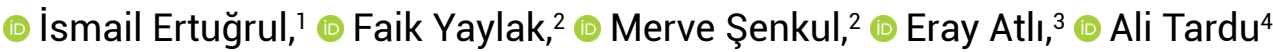 \\ 'Department of Gastrointestinal Surgery, Evliya Çelebi Training and Research Hospital, Kütahya, Turkey \\ ${ }^{2}$ Department of General Surgery, Dumlupınar University Faculty of Medicine, Kütahya, Turkey \\ ${ }^{3}$ Department of Radiology, Okan University Faculty of Medicine, İstanbul, Turkey \\ ${ }^{4}$ Department of Gastrointestinal Surgery, Sultan Murat-I Public Hospital, Edirne, Turkey
}

\begin{abstract}
Laparoscopic sleeve gastrectomy (LSG) is a common surgical procedure for the treatment of morbid obesity. Severe complications may result with significant morbidity and mortality. Staple-line leakage is a rare, but important, complication. Here we present the case of a patient with staple-line leakage after LSG who was treated conservatively. The patient was a 36-year-old female with a body mass index of 43. LSG was performed. The postoperative course was uneventful and the patient was discharged on postoperative day 3. She presented with fever and back pain on postoperative day 5 . An intermediate, type 2 staple-line leak was confirmed with computed tomography (CT). The patient was treated conservatively. The patient was well 1 year after the initial treatment and a follow-up CT confirmed complete resolution. Leakage and related morbidity and mortality after LSG may be a challenge for the patient and the surgeon. Early diagnosis and aggressive treatment is essential to overcome potential serious consequences. In some selected patients, a conservative approach with close observation may help to manage leakage after LSG.
\end{abstract}

Keywords: Laparoscopic sleeve gastrectomy; leakage; morbid obesity.

\section{Introduction}

Laparoscopic sleeve gastrectomy (LSG) is a common surgical procedure for the treatment of morbid obesity. ${ }^{[1]}$ Initially the procedure was defined as a part of duodenal switch and bilioenteric diversion, but was recognized as a sole procedure for. ${ }^{[2]}$ LSG has lower rates of morbidity, however complications may be severe and result with mortality. ${ }^{[3]}$ Leak is the most important complication after LSG with reported rates between $0.7-5 \% .{ }^{[4]}$ Prompt diagnosis and aggressive treatment are essential to minimize chronic gastric fistula, multiple organ failure and related mortality rates ${ }^{[5]}$ Computed tomography is not only useful in the dignosis but also is may be useful treatment with drainage. The conservative approach can be done in the context of computerized tomography (CT) drainage, broad-spectrum antibiotics, total parenteral nutrition (TPN). In this case report a conservative management of stapler line leakage after LSG was presented.

\section{Case Report}

A 36 years old woman with BMI 43 was treated with LSG. The patient was morbid obese for the last 17 years with 
Type 2 DM (was regulated with oral antidiabetics), and asthma. Intra-operative routine methylene blue test was negative. Nasogastric tube was withdrawn after methylene blue test. On postoperative day one metilen blue test was negative and oral water only was begun. On postoperative day two metilen blue test was repeated and was negative and the drain was removed. Patient was discharged on postoperative day three. On postoperative day five the patient was presented with back pain and fever. Leukocyte count and CRP were elevated. Abdominal examination was not relevant. Computed tomography has demonstrated free abdominal gas and contrast extravasations at level of fundus (Fig. 1). Percutanous drainage was not feasible due to the localization. Oral intake was restricted

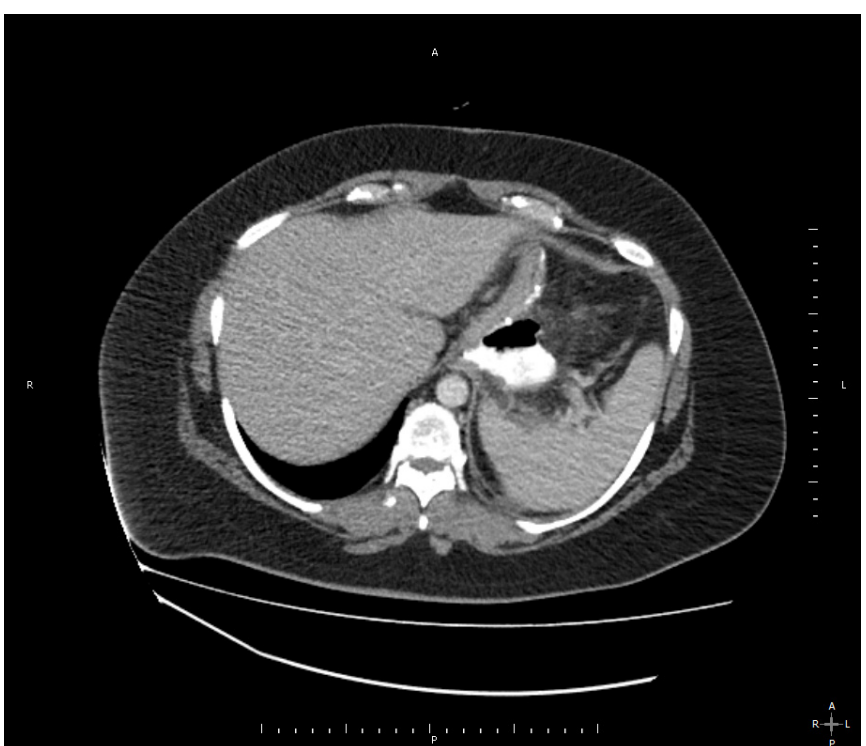

Figure 1. Contrast extravsation at the level of fundus, contrast enhanced computed tomography.

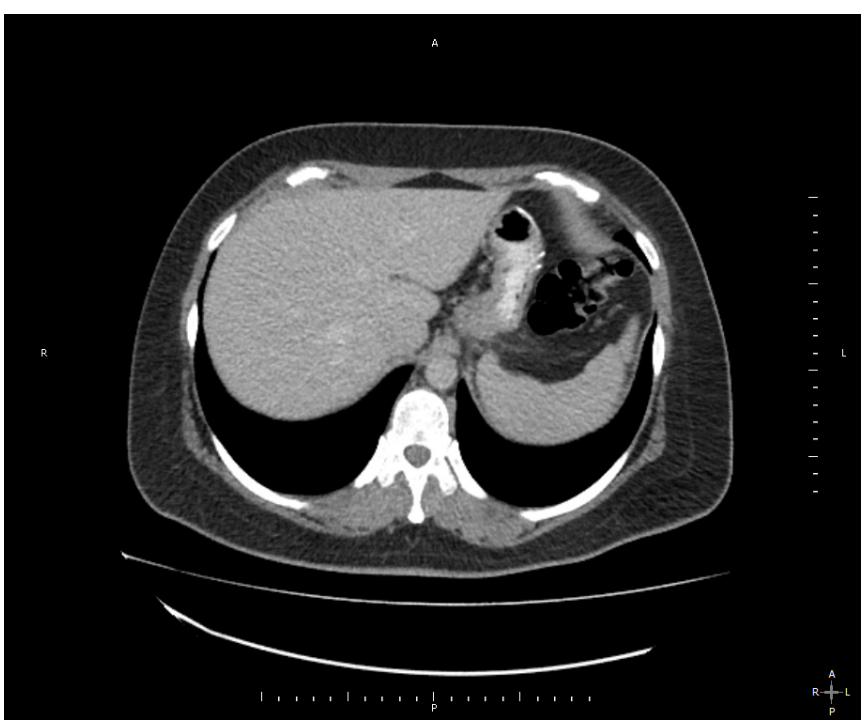

Figure 2. Complete resolution after one year follow, contrast enhanced computed tomography. and TPN was began with parenteral meropenem . After a course of 14 days of conservative treatment the patient did well, CT demonstrated regression of the collection. Thus oral intake was begun and patient tolerance was well. Patient was discharged and CT control after one year was clear (Fig. 2). Control BMI was 32.8 and excess weight loss was $57.7 \%$ and DM was resolved.

\section{Discussion}

LSG may be considered more doable than gastric bypass. ${ }^{[6]}$ However, surgical technique is important to minimize surgical complications. Meticulous dissection and tissue handling, tissue stapler coherence, and adequate homeostasis are cornerstones of surgical technique. Inadequate healing of stapler line, decreased blood flow, infection, ischemia, and inadequate oxygenisation are risk factors for leakage. Classical ischemic leakage occurs 5-7 days after surgery. ${ }^{[7]}$ Extra luminal gastric leakage, fistula, peritonitis, abscess, sepsis, organ failure and mortality may occur. Leakage may be asymptomatic with radiologic findings or may manifest with septic shock and multiorgan failure leading to death. Subclinical leakages are defined as type 1 and clinical leakages are type 2 . Csendes et al..$^{[8]}$ defined postoperative leakages early if occurred on one to three days, intermediate if occurred in four to seven days and late for those manifested after eight days. Our case was an intermediate leakage that occurred on postoperative day five. Type 2 leakage was observed with fever, back pain, and leukocyte and CRP elevations. Diagnosis was confirmed with CT and conservative management was begun and patient response was well. However it is important to remember that for those patients no needs further treatment after three months surgery should be considered. Early leakages may require abdominal lavage, drainage and suture management of stapler line leakages. ${ }^{[9]}$ Intermediate and late leakages may also need such surgical approaches. ${ }^{[10]}$

Endoscopic interventions may have significant place in the management of leakage after LSG. Endoscopic stenting, fibrin glue, clips or nasojejunal feeding catheter placements are important procedure to help the patient. ${ }^{[11]}$

\section{Conclusion}

As a conclusion, leakage and related morbidity and mortality after LSG may be a challenge for the patient and surgeon. Early diagnosis and aggressive treatment is essential to overcome potential consequences. In some selected 
patients conservative approach with close observation may help to manage the leakage after LSG.

\section{Disclosures}

Informed Consent: Written informed consent was obtained from the patient for the publication of the case report and the accompanying images.

Peer-review: Externally peer-reviewed.

Conflict of Interest: None declared.

\section{References}

1. Angrisani L, Santonicola A, lovino P, Formisano G, Buchwald $\mathrm{H}$, Scopinaro N. Bariatric Surgery Worldwide 2013. Obes Surg 2015;25:1822-32. [CrossRef]

2. Hess DS, Hess DW. Biliopancreatic diversion with a duodenal switch. Obes Surg 1998;8:267-82. [CrossRef]

3. Chang SH, Stoll CR, Song J, Varela JE, Eagon CJ, Colditz GA. The effectiveness and risks of bariatric surgery: an updated systematic review and meta-analysis, 2003-2012. JAMA Surg 2014;149:275-87. [CrossRef]

4. Moszkowicz D, Arienzo R, Khettab I, Rahmi G, Zinzindohoué $\mathrm{F}$, Berger $\mathrm{A}$, et al. Sleeve gastrectomy severe complica- tions: is it always a reasonable surgical option? Obes Surg 2013;23:676-86. [CrossRef]

5. Sakran N, Goitein D, Raziel A, Keidar A, Beglaibter N, Grinbaum $\mathrm{R}$, et al. Gastric leaks after sleeve gastrectomy: a multicenter experience with 2,834 patients. Surg Endosc 2012;27:240-5.

6. Shi X, Karmali S, Sharma AM, Birch DW. A review of laparoscopic sleeve gastrectomy for morbid obesity. Obes Surg 2010;20:1171-7. [CrossRef]

7. Baker RS, Foote J, Kemmeter P, Brady R, Vroegop T, Serveld M. The science of stapling and leaks. Obes Surg 2004;14:12908. [CrossRef]

8. Csendes A, Burdiles P, Burgos AM, Maluenda F, Diaz JC. Conservative management of anastomotic leaks after 557 open gastric bypasses. Obes Surg 2005;15:1252-6. [CrossRef]

9. Aurora AR, Khaitan L, Saber AA. Sleeve gastrectomy and the risk of leak: a systematic analysis of 4,888 patients. Surg Endosc 2012;26:1509-15. [CrossRef]

10. Csendes A, Braghetto I, León P, Burgos AM. Management of leaks after laparoscopic sleeve gastrectomy in patients with obesity. J Gastrointest Surg 2010;14:1343-8. [CrossRef]

11. Papavramidis TS, Kotzampassi K, Kotidis E, Eleftheriadis EE, Papavramidis ST. Endoscopic fibrin sealing of gastrocutaneous fistulas after sleeve gastrectomy and biliopancreatic diversion with duodenal switch. J Gastroenterol Hepatol 2008;23:1802-5. [CrossRef] 